\title{
The Learning Burden- Problem of Curriculum Load
}

\author{
Dr. Kadambari Naniwadekar ${ }^{1}$
}

\section{ABSTRACT}

Concerns regarding academic burden on students, especially students with special needs and unsatisfactory quality of learning has been talked about time and again. The problem has been discussed extensively by several committees, with several recommendations on reducing the academic burden on the students. But instead, the problem has grown more acute with the passing time and increased competition. This problem of academic burden manifests itself in many ways for our children with special needs, the most common being behaviour problems and sometimes academic under achievement. The situation has become worse over the years even with children both typically developing and with special needs attending pre- schools carrying a bag full of books and notebooks.

It is very hard to reconcile the rigorous 'academic' regime that is imposed on children with hearing impairment from an early age with the widespread complaint made about moving at the same pace with the typically developing children and competitive ethos of the later school years. The pernicious grip of this false argument manifests itself in strange preschool and primary schools practices like early emphasis on shapely writing, memorizing information and so on. One message of this situation is that both the child and the teacher have lost the 'joy of learning'. This study aimed at investigating the impact of overload or academic burden of the curriculum on children with hearing impairment and how it affects the psychological well being of these children. The study proposed to develop tool to identify the factors leading to stress in these children with special needs and then correlate with the academic performance and behaviour problems, if any.

Keywords: Curriculum, Overload, Learning, Special Needs

Children with special needs have the right to education just as any other typically developing child. Inclusive education strives to address the learning needs of the children with special needs. The philosophy behind inclusive education being to promote opportunities for all children to participate, learn and have equal treatment, irrespective of their mental or physical abilities.

\footnotetext{
${ }^{1}$ Special Educator, All India Institute of Speech and Hearing, Mysuru, India *Responding Author

(C) 2016 Naniwadekar K; licensee IJIP. This is an Open Access Research distributed under the terms of the Creative Commons Attribution License (http://creativecommons.org/licenses/by/2.0), which permits unrestricted use, distribution, and reproduction in any Medium, provided the original work is properly cited.
} 


\section{The Learning Burden- Problem of Curriculum Load}

While the awareness on Inclusive Education is at a nascent stage throughout our country, educational institutions are somewhat skeptical about having these children in their classrooms.

According to Chimedza and Peters (2001), inclusion was effectively realized only after the Salamanca World Conference (1994). This statement, which was adopted by the representatives of 92 governments and25 international organisations in June 1994, has definitely set the policy agenda for inclusive education on a global basis (UNESCO, 1994).

To make inclusive education possible, and to better accommodate students with different learning abilities, the present education system, educational structure, and educational practices need to become more flexible, more inclusive, and more collaborative. The purpose of inclusive education is not to bring students with Special Education Needs up to the level of typically developing children but it is to meet the individualised goals of students with special educational needs, within the context of general education setting and activities.

But the problem in developing countries like India, is that "a lot is taught, but of which only a little is understood or learnt". This kind of teaching that is happening in the Indian schools leads to what we call as curriculum overload. Overload has been defined as too great a load (Webster, 2000). The phrase curriculum overload suggests that some imbalance or incongruity between our capacity to enact or activate a curriculum which itself is perceived as overloaded.

The situation of overload has become worse over the years, with preschoolers carrying bag of books and notebooks at such an early age. Leisure has become a highly scarce commodity, in child's life, be it in the urban or rural setup. The child's innate nature and capacities have no opportunity to find expression. It is very hard to reconcile the rigorous academic regime that is imposed on children and especially to children with any special needs from an early age is the widespread complaint. Covering the syllabus has become an end in itself. Both the teacher and the child have lost the sense of joy involved in the education process. Teaching and Learning have both become a chore for most of the children. Despite official stipulations that no textbooks be used at an early age, most of the preschool teachers and parents in the urban centres are feeling compelled to burden the young child. The sense of compulsion comes from the widespread feeling among the parents of children with hearing impairment that unless rigorous academic training starts early, their child will not be able to cope with the fast paced pedagogy and the competitive later years of schooling.

The pernicious grip of this false argument manifests itself in strange preschool and primary schools practices like early emphasis on shapely writing, memorizing information and so on. One message of this situation is that both the child and the teacher have lost the 'joy of learning'. This overemphasis to study and be at the same level as their typically developing counterparts in posing a great cause for various behavioural problems in any child and especially more so if the 
The Learning Burden- Problem of Curriculum Load

child has a disability. A child with hearing impairment having almost normal intelligence is hence pressurized to study much more than their typically developing sibling, just because he/she has to get ready to move into the big world and that the child should not lack behind.

With this situation in mind, the study was conducted to find out if we as a teacher are overburdening the child with too much of academic tasks and if so, then is it leading to any problem.

\section{Aims \& Objectives}

The primary purpose of the study was to survey the effect of curriculum overload on children with hearing impairment receiving education in mainstream schools. This purpose was realised through systematic materialisation of the following objectives:

- Preparing a tool for psychological wellbeing to suit Indian conditions.

- Carrying out a survey of prevalent educational status of mainstreamed children with hearing impairment.

- Gathering information about academic achievement of children with hearing impairment.

- Probing the effect of curriculum load on children's academic achievement and its behavioural manifestations, if any.

\section{METHODOLOGY}

With the need of the study in mind a checklist was developed to assess the effect of curriculum load on children with hearing impairment. The checklist consisted of 20 items. It was given to 5 reviewers with a qualification of masters in education for validation and the suggestions received were incorporated in the final version.

Once the checklist was ready, it was administered on parents/caregivers of children with hearing impairment studying in mainstream/special schools, to see how much pressure they put on their child for studying.

A survey type of research was conducted at the Department of Special Education, All India Institute of Speech and Hearing, Mysuru with an assumption that children with hearing impairment are overloaded with academics and that it has a negative effect on their mind as well as leading to various behavioural manifestations. After receiving the data it was analyzed qualitatively to check for the results.

\section{Participants}

The study included 27 primary caregivers that are mothers of children with hearing impairment and their wards. The selection criteria was that the children should be receiving primary education in mainstream/special schools. Most of the schools were situated in an around city of Mysuru.

(c) The International Journal of Indian Psychology, ISSN 2348-5396 (e) | ISSN: 2349-3429 (p) | 7 


\section{The Learning Burden- Problem of Curriculum Load}

\section{Data Collection and Analysis}

The actual study was conducted by getting the checklist self-administered by the caregiver participants, all of whom happened to be mothers. Once caregiver data was received, as a next step the academic records of each child was perused to compile details about the aggregate level of academic achievement of these children in their respective schools and a behavioural profile was also obtained to check for any deviations in the behaviours of these children. After receiving the data, it was analysed using SPSS to find out the correlation between curriculum overload and children's academic achievement and its behavioural manifestations thereby deriving the results of the study.

\section{RESULTS}

After receiving the results they were analyzed. The results hence found were:

1. All the children with hearing impairment enjoyed schooling, and liked to go school daily, and even on holidays.

2. Most of the children with hearing impairment were in appropriate class as per their age, while only $20 \%$ of the total sample was in the class lower than their age.

3. Almost all, except 3 children from the sample were able to manage their studies, as per their mother's perception.

4. 24 mothers out of the total 27 , were of the view that what was being taught in their child's school was sufficient for them. Although they were of the opinion that although it was more than what is being taught to their typically developing child, but as these children were special, they should be taught more, so as to compete in this world.

5. Almost half the parents send their child to tuition/extra classes, so that they learn more than their peers, as the competition is increasing day by day, and they don't want their child to lack behind.

6. Most of the children enjoyed doing homework, while $25 \%$ of them showed temper tantrums if asked to do home work.

7. $70 \%$ of the parents admitted that they forced their child to study, as they didn't want society to make fun of their child.

8. When asked, if the amount of pressure they put on their child, cause stress to their child, $70 \%$ of the mothers said yes. That shows that the mothers/ parents are overloading their child with their over expectations.

9. This stress is not just limited to the child, as almost $49 \%$ of the mothers from the sample too experienced stress due to their child's education.

10. When asked if they were putting extra stress on their child as s/he was a child with special needs, $51 \%$ of them accepted it, and gave a reason that if they don't do it, their child will lack behind and then will not be able to lead better life.

11. Out of 27 children assessed, $40 \%$ of them showed problem behaviours due to over load of studies and excessive pressure from the parents, but the mothers said that they were able to manage these behaviours themselves. 


\section{The Learning Burden- Problem of Curriculum Load}

12. When enquired about the behaviour management techniques, $81 \%$ of the mothers reported physical punishment to be the best and $40 \%$ of the mothers used physical punishments very frequently to manage their child.

13. $85 \%$ of the parents felt that if the teachers in their child's regular play-school/primary schools teach through play way method, their child will learn better, and with little stress.

14. Lastly, when asked if the schools, teachers and parents should give less pressure to the child, all the respondents, except 2 said no. They felt that if we don't pressurize these kids with special needs, they won't be able to cope with the schooling and sustain in this competitive world.

\section{DISCUSSION}

From the above results, it can be inferred that children with hearing impairment, enjoy schooling as any other typically developing child. The results also highlighted the fact that many mainstream schools in Mysuru district are open to Inclusive Education.

This being the case the results however also through light on the fact that like any other child in mainstream classrooms, these children with special needs are also burdened with excessive curriculum, thereby overloading them. Another glaring fact that has been revealed in the results, highlight the fact that parents of children with special needs, consider overloading their child with studies as acceptable, as they want their child to run in the same race as any other typically developing child would. Although there is nothing wrong in aiming high for their child, parents should keep in view the problem that their child suffers from.

The results also indicated that like other parents, most of the parents of children with special needs take their child for tuitions and extra classes. Another point that was found in the results was the fact that this curriculum load is not just hampering the wellbeing of these special children, but at the same time giving a lot of stress to their parents also. This stress in turn is leading to severe punishments by the parents to their child with special needs. The stress seen in the parents, especially the mothers, is not just limited to themselves, but hampering their family life as well.

Last but not the least, the results again reiterated the fact that in the present day world, like any other parent, our parents of children with special needs are also blindly running in the race. Although that this overload is causing serious behavioural issues in their child with special needs, but that does not stop from overburdening the child.

These practices are not only leading to academic under achievement and behaviour problems but also stealing childhood from a child's life. 
The Learning Burden- Problem of Curriculum Load

\section{Acknowledgments}

The author appreciates all those who participated in the study and helped to facilitate the research process.

\section{Conflict of Interests}

The author declared no conflict of interests.

\section{REFERENCES}

Chimedza, R. and Peters, S. (2001).Disability and special education in African context different voices. Harare: College Press.

Salamanca World Conference, 1994. Special needs education framework for action statement. Salamanca: Longman.

UNESCO, 1998. Inclusive education in developing countries. New York: Maxell MacMillan International.

Webster (2000). Webster's New World. College Dictionary. Fourth edition. Cleveland, Ohio: IDG books worldwide Inc.

How to cite this article: Naniwadekar K (2016), The Learning Burden- Problem of Curriculum Load, International Journal of Indian Psychology, Volume 4, Issue 1, No. 83, ISSN:2348-5396 (e), ISSN:2349-3429 (p), DIP:18.01.161/20160401, ISBN:978-1-365-64761-1 